Conf-9505105-11

UCRL-JC- 119969

PREPRINT

\title{
Electromagnetic and Thermal Analysis of Distributed Cooled High Power Millimeter Wave Windows
}

\author{
Scott D. Nelson \\ Thomas Reitter \\ Malcolm Caplan \\ Lawrence Livermore National Laboratory \\ Charles Moeller \\ General Atomics
}

This paper was prepared for submittal to:

Eleventh Topical Conference on Radio Frequency Power in Plasmas,

Palm Springs, California

May $17-19,1995$

May 12, 1995

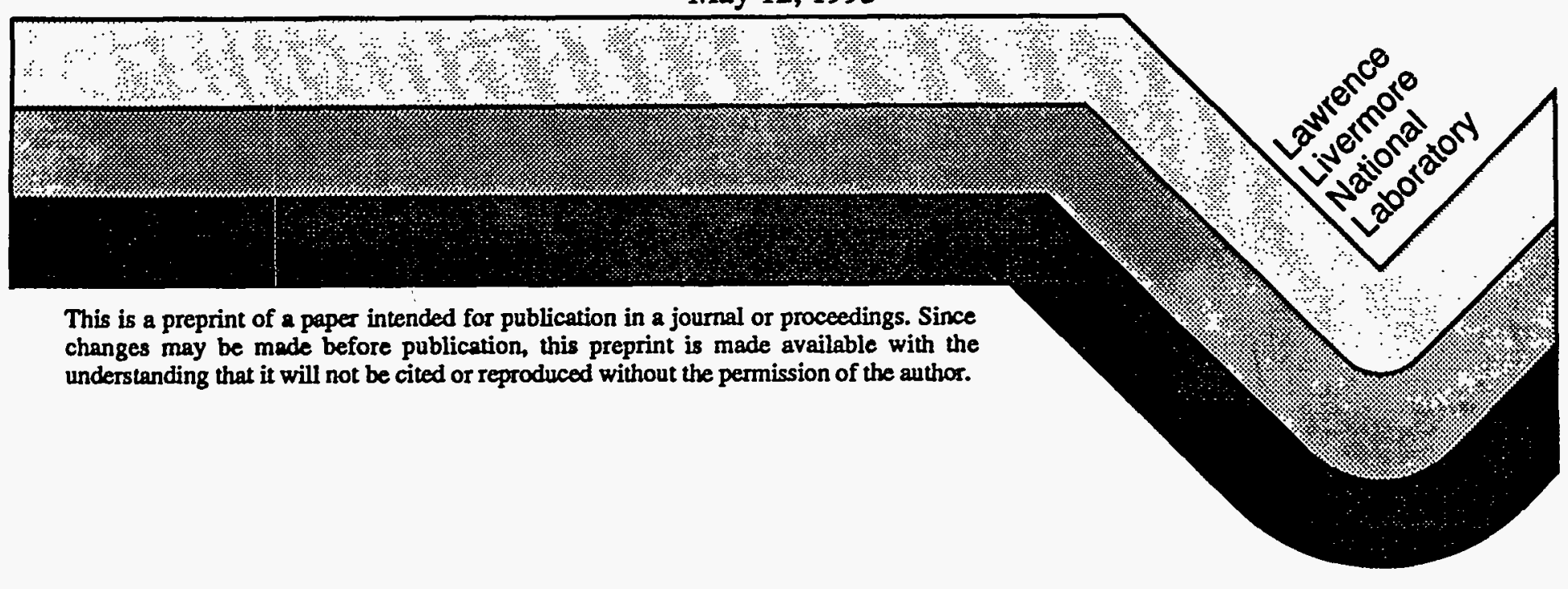

RFCFIVED

DISTPIBUTION OF THIS DOCUMENT IS UNLIMITED

AUG 041995

ya

OSTI

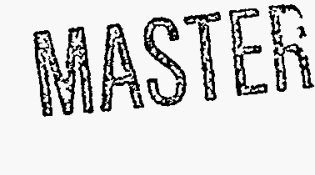




\section{DISCLAIMER}

This document was prepared as an account of work sponsored by an agency of the United States Government. Neither the United States Government nor the University of California nor any of their employees, makes any warranty, express or implied, or assumes any legal liability or responsibility for the accuracy, completeness, or usefulness of any information, apparatus, product, or process disclosed, or represents that its use would not infringe privately owned rights. Reference herein to any specific commercial products, process, or service by trade name, trademark, manufacturer, or otherwise, does not necessarily constitute or imply its endorsement, recommendation, or favoring by the United States Government or the University of California. The views and opinions of authors expressed herein do not necessarily state or reflect those of the United States Government or the University of California, and shall not be used for advertising or product endorsement purposes.

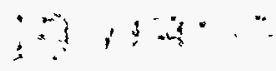

$$
\begin{aligned}
& \text { ip! : : : }
\end{aligned}
$$




\section{DISCLAIMER}

Portions of this document may be illegible in electronic image products. Images are produced from the best available original document. 


\title{
Electromagnetic and Thermal Analysis of Distributed Cooled High Power
Millimeter Wave Windows
}

\author{
Scott D. Nelson, Tom Reitter, Malcolm Caplan*, \\ and Charles Moeller $†$ \\ *Lawrence Livermore National Laboratory and †General Atomics
}

\begin{abstract}
The sectional high-frequency internally-cooled window, as proposed by General Atomics(1), has unique potential for allowing microwave sources to reach multi-megawatt $\mathrm{CW}$ levels with application to ECRH. Designs are being investigated using computational electromagnetic (EM), thermal, and mechanical codes at $110 \mathrm{GHz}$ and $170 \mathrm{GHz}$ to examine the design tradeoffs between RF performance and thermal mechanical safety margins. The EM analyses are for the window, under vacuum at one $M W$ and includes variations in the shapes of the cooling fins, the surface treatment of the window elements themselves, the cooling fin tip treatment, the window pitch angle, and the waveguide effects. One advantage of the distributed cooled window is it's extensibility to higher power levels.

Results in the modeling efforts are presented showing the EM field concentrations (which then will feed into the thermal analysis), the energy scattering/reflection, the transmitted launch angle variation as a function of physical geometry, and the spatial energy distribution and loss as a function of time and position.
\end{abstract}

\section{INTRODUCTION}

Work has been performed in the design, modeling, and fabrication of distributed cooled windows for multi-megawatt high frequency applications in the 110 and 170 $\mathrm{GHz}$ regimes. These windows consist of dielectric slabs separated by metallic cooling fins with tapered ends. Initial efforts have been concentrating on $1 \mathrm{MW}$ power level designs but results with experimental units performed previously(1) show good potential for scalability to higher power levels. Thermal-mechanical and EM modeling is being utilized to address the scalability issues. 


\section{THERMAL-MECHANICAL MODELING}

The initial results of the thermal and stress/strain calculations were obtained using 2-D analysis codes for a subsample of the cells in the distributed cooled window array.

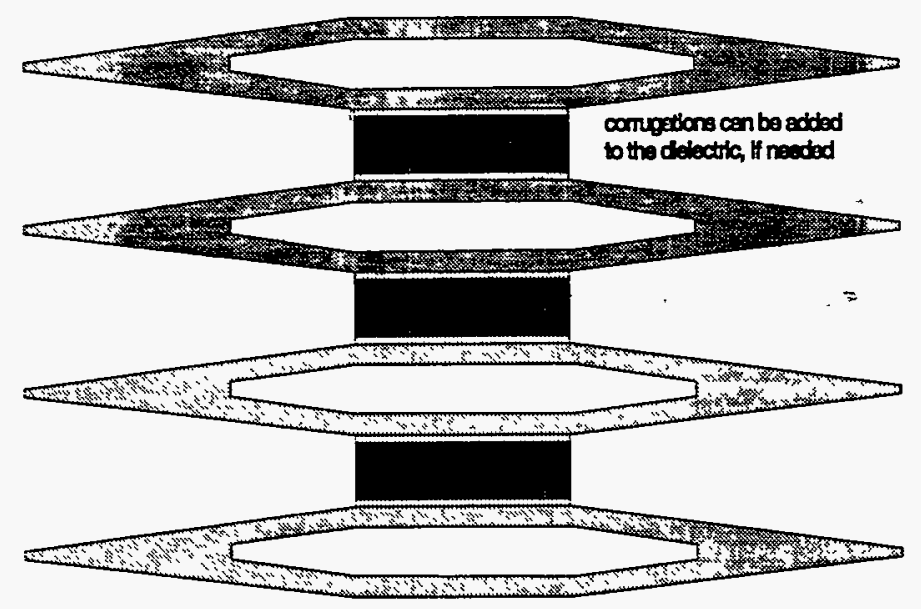

FIGURE 1. Three cells of the distributed cooled window. Power flow is from left to right.

The sapphire dielectric elements are brazed to the metallic cooling fins to prevent vacuum or coolant loss. The water coolant makes a single pass through the cooling fins under pressure and is responsible for not only dissipating the heat from the dielectric but also from the cooling fin tips. The cooling fin wall thickness is one of the constraints on the cooling channel size.

During the RF exposure, the dielectric (via absorption heating) and cooling fins (via ohmic heating) heat up disproportionally to the rest of the structure and stress / strain calculations were performed to gauge the severity of these effects.

\section{Thermal Calculations}

The calculations to date have been 2-D and steady state. This simplification rests on the empirical observation that the coolant in a prototype cell only heats up a "few" degrees. The assumption is that the coolant temperature remains at a constant 298 $\mathrm{K}$ and therefore represents a constant heat transfer coefficient between the niobium and the water. 
TABLE 1. Thermal-mechanical material properties

\begin{tabular}{|l|r|r|r|r|r|r|r|c|}
\hline Material & $\begin{array}{c}\rho \\
\left(\mathrm{kg} / \mathrm{m}^{3}\right)\end{array}$ & $\begin{array}{c}\mathrm{k} \\
(\mathrm{W} / \mathrm{mK})\end{array}$ & $\begin{array}{c}\alpha \\
\left(10^{-6} \mathrm{~K}^{-1}\right)\end{array}$ & $v$ & $\begin{array}{c}\mathrm{E} \\
(\mathrm{GPa})\end{array}$ & $\begin{array}{c}\sigma_{\mathrm{y}} \\
(\mathrm{MPa})\end{array}$ & $\begin{array}{c}\sigma_{\text {uen }} \\
(\mathrm{MPa})\end{array}$ & $\mathrm{P}_{\text {diss }}$ \\
\hline Niobium & 8570 & 50.2 & 7.3 & 0.38 & 103.0 & 207.0 & 275 & $52 \%$ \\
\hline Gold & 19300 & 315.0 & 14.2 & 0.42 & 74.5 & 6.9 & 125 & $33 \%$ \\
\hline Sapphire & 3980 & 27.2 & 8.0 & 0.23 & 430.0 & $\begin{array}{r}\text { not } \\
\text { def. }\end{array}$ & 450 & $15 \%$ \\
\hline
\end{tabular}

The power absorbed in the sapphire is calculated from(2)

$$
\frac{P_{a}}{P_{0}} \cdot\left(\frac{k_{0} L}{2}\right)\left(1, \epsilon_{r}\right) \text { tans, }
$$

where $P_{o}$ is the incident power, $P_{a}$ is the absorbed power, $k_{o}$ is the free space wavenumber, $\left(k_{o}\right.$ in $\mathrm{cm}^{-1}$ is given by $k_{o}=0.2096 f$, for $f$ in $\left.\mathrm{Ghz}\right), L$ is the thickness of the sapphire in the z-direction, $\epsilon_{r}$ is the permittivity, and $\tan \delta$ is the loss tangent. For $\epsilon_{r}=9.0, \tan \delta=2.5 \cdot 10^{-4}$, we find $P_{a} / P_{o}=0.0078$ for $f=110 \mathrm{GHz}(L=0.27$ $\mathrm{cm})$ and $P_{a} / P_{o}=0.0103$ for $f=170 \mathrm{GHz}(L=0.23 \mathrm{~cm})$. For a total power of $1 \mathrm{MW}$ and 23 cells, $P_{0}=43.5 \mathrm{~kW}$ and the power absorbed / volume is $3.37 \mathrm{GW} / \mathrm{m}^{3}$ at 110 $\mathrm{GHz}$ and $6.85 \mathrm{GW} / \mathrm{m}^{3}$ at $170 \mathrm{GHz}$.

Table 2 presents the results for the 110 and $170 \mathrm{GHz}$ cases. The maximum temperatures for the cooling channel material was in the tip region which was at the farthest point from the coolant and is the first part of the window in the RF input stream.

TABLE 2. Maximum temperatures in various components

\begin{tabular}{|c|c|c|c|}
\hline frequency & $\mathrm{h}_{\text {water }}\left(\mathrm{MW} / \mathrm{m}^{2} \mathrm{~K}\right)$ & $\mathrm{T}_{\max } \mathrm{Nb}(\mathrm{K})$ & $\mathrm{T}_{\max }$ sapphire $(\mathrm{K})$ \\
\hline $110 \mathrm{GHz}$ & 0.124 & 375.3 & 382.3 \\
\hline $170 \mathrm{GHz}$ & 0.124 & 405.9 & 407.3 \\
\hline
\end{tabular}

The peak temperature in the tip is proportional to $\tan \theta$, where $\theta$ is the angle at the base of the tip. Further studies involved changing the internal cooling channel geometry including ribbed configurations. The conclusion was that maximum tip temperature is reduced by changing $\theta$ or by decreasing the distance from the cooling channel inner wall to the tip. This illustrates two points: the results may be sensitive to seemingly minor changes, which presents an opportunity to optimize the design, but they may be overly sensitive to manufacturing tolerances, which is undesirable. 

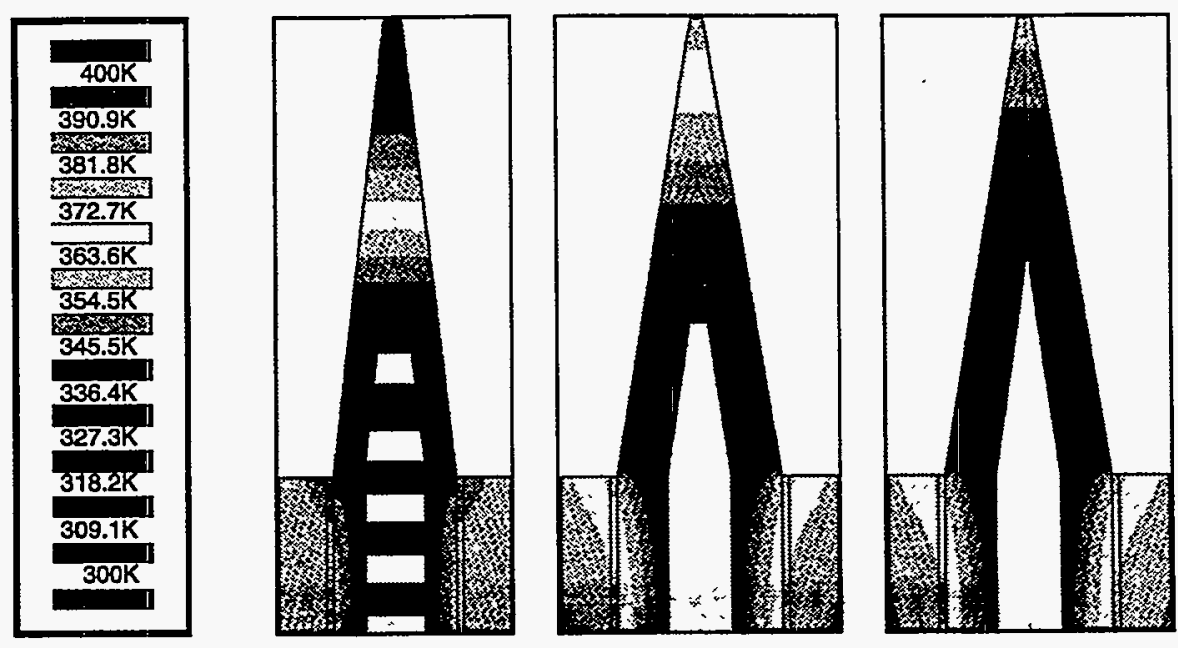

FIGURE 2. Thermal distributions in the window for several different cooling channel configurations.

In no case is the temperature per se high enough to be a problem. Possible concerns are thermal stresses causing deflection of the $\mathrm{Nb}$ tips, or cracks in the braze or sapphire. Deflection would only be calculated for an asymmetric loading, which would require 3D modeling of the entire niobium waveguide and coolant channel. The modeling of fatigue effects, however, would require many assumptions.

\section{Stress / Strain Calculations}

The stress calculations were performed using the thermal results noted above. The effective stress for the (relatively) ductile $\mathrm{Nb}$ and the maximum principal stress for the brittle sapphire are shown in Table 3. It is seen that the calculated stresses are much less than the tensile strengths of the materials.

TABLE 3. Effective stress and maximum principal stress for the Niobium and Sapphire window components.

\begin{tabular}{|c|c|c|c|c|}
\hline \multirow{2}{*}{$\begin{array}{c}\text { frequency } \\
(\mathrm{GHz})\end{array}$} & \multicolumn{2}{|c|}{$\begin{array}{c}\text { Plane Stress, } \\
(\mathrm{MPa})\end{array}$} & \multicolumn{2}{c|}{$\begin{array}{c}\text { Plane Strain, } \\
(\mathrm{MPa})\end{array}$} \\
\cline { 2 - 5 } & Niobium & Sapphire & Niobium & Sapphire \\
\hline 110 & 25.4 & 23.4 & 58.0 & 23.6 \\
\hline 170 & 15.0 & 25.2 & 80.8 & 23.1 \\
\hline
\end{tabular}


The 2-D calculations of necessity neglect asymmetries and edge effects, which may be particularly important for stresses. A key assumption, based on empirical evidence for a similar window, is that the water coolant temperature only increases a few degrees. For the calculated power that the water must remove, we would expect a noticeable rise, which would require a 3-D calculation. (Fortunately, $\mathrm{h}$ increases significantly with water temperature, which should help alleviate the effect of the reduction in heat transfer that a smaller $\Delta \mathrm{T}$ would suggest.)
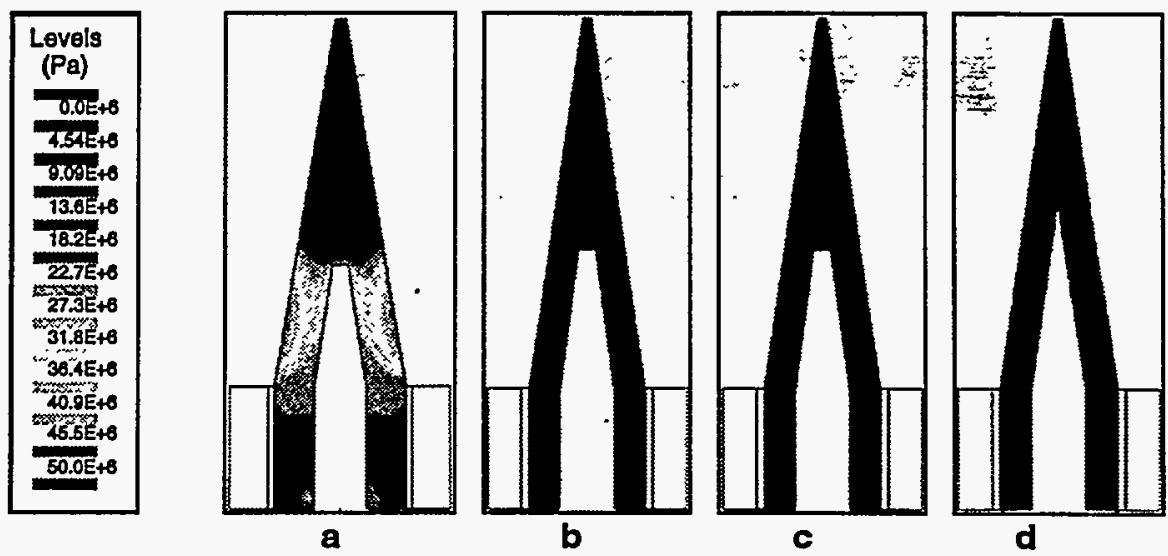

FIGURE 3. Effective stress distribution in the cooling fin for (a) $110 \mathrm{GHz}, \mathrm{h}=0.0124$ $\mathrm{MW} / \mathrm{m}^{2} \mathrm{~K}$, (b) $110 \mathrm{GHz}, \mathrm{h}=0.085 \mathrm{MW} / \mathrm{m}^{2} \mathrm{~K}$, (c) $170 \mathrm{GHz}, \mathrm{h}=0.085 \mathrm{MW} / \mathrm{m}^{2} \mathrm{~K}$, (d) $170 \mathrm{GHz}$, $\mathrm{h}=0.124 \mathrm{MW} / \mathrm{m}^{2} \mathrm{~K}$.
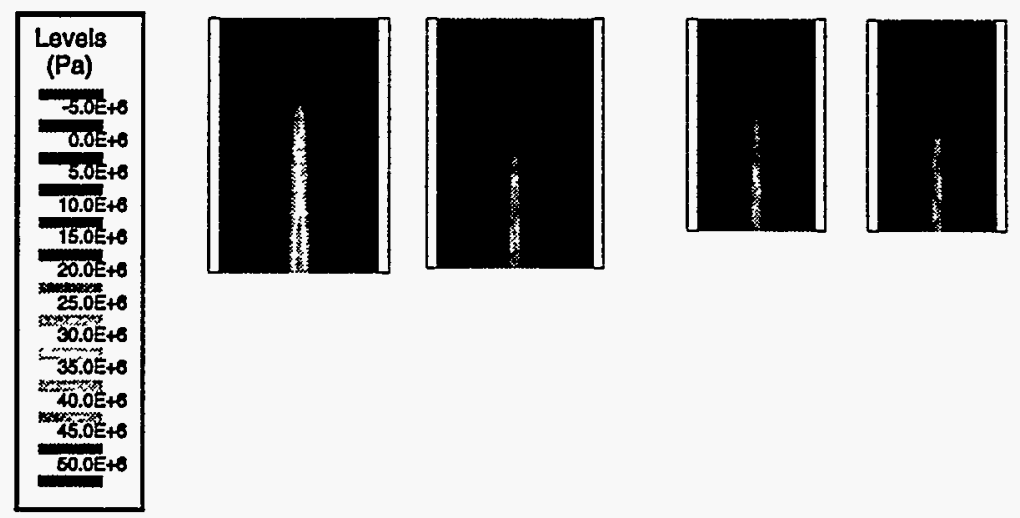

a

b

c

d

FIGURE 4. Maximum principal stress distribution in the dielectric for (a) $110 \mathrm{GHz}$, $h=0.0124 \mathrm{MW} / \mathrm{m}^{2} \mathrm{~K}$, (b) $110 \mathrm{GHz}, \mathrm{h}=0.085 \mathrm{MW} / \mathrm{m}^{2} \mathrm{~K}$, (c) $170 \mathrm{GHz}, \mathrm{h}=0.085 \mathrm{MW} / \mathrm{m}^{2} \mathrm{~K}$, (d) $170 \mathrm{GHz}, \mathrm{h}=0.124 \mathrm{MW} / \mathrm{m}^{2} \mathrm{~K}$. 


\section{ELECTROMAGNETIC MODELING}

The distributed cooled window has several electrical advantages over conventional window designs which include high power operation, operation in several frequency bands, and scalability. EM modeling of the window system included examining the cooling fin tip effects on the window's performance, the dielectric reflections and wave compression, the grating diffraction for higher frequency components, the effects of changing the tip pitch angle, and the window reflection coefficient vs. frequency.

\section{EM Modeling Codes}

The electromagnetic modeling efforts centered on using the 2.5D Finite Difference Time Domain (FDTD) EM modeling codes(3) developed at LLNL over the course of several years. These codes have also been used as part of other EM modeling efforts(4). The 2.5D codes simulate either axisymmetric problems (coaxial or beam pipe geometries) or rectangular systems (for classical 2D FDTD EM studies) and can include terms for frequency dependent dispersive electric or magnetic media.

Since the FDTD codes use a regular cell structure, initial activities were performed to gauge the noise level of a classical single disk window compared to the analytic solution. Since the geometry of this configuration lies along the principal axes of the model space then the solution was expected to be limited by computational noise and sampling errors.

TABLE 4. Reflected power noise comparison between FDTD EM code for a simple single disk window compaired to the analytic result.

\begin{tabular}{|l|c|c|}
\hline & analytic solution & FDTD model \\
\hline $\begin{array}{l}\text { center band power } \\
\text { reflection }\end{array}$ & $0 \%$ & $0.03 \%$ \\
\hline
\end{tabular}

\section{Cooling Fin Tip Treatment}

The cooling fin tip treatment is limited by manufacturability limits, the desire to limit the reflectance from the tips, and the requirement to cool the tips. These trade-offs tend to push against each other. 


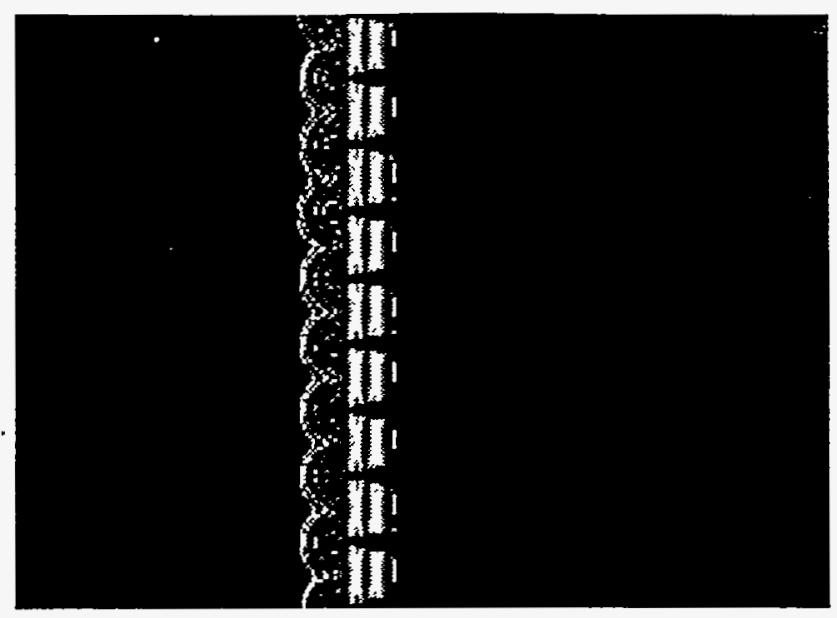

FIGURE 5. Temporal early time field values show tip scattering effects.

These tip effects can be seen most dramatically in the early time wave propagation models (Figure 5). In this case, an RF pulse is used to illustrate the scattering nature of the cooling fin tips. These expanding wavefronts constructively and destructively interfere to create "hot spots" in regions near the window. At further distances, this effect diminishes.

\section{FDTD modeling of the tapered structures}

One potential problem when using regular-cell grid codes is the difficulty in simulating surfaces that are curved or non-aligned with the coordinate axes. In the case of the distributed cooled window, this could potentially be a severe problem since the main structure of the cooling fins is slanted. In preliminary work in an effort to gauge the base reflectance of many of the metal structures and the cooling fin features, the window was modeled without any dielectric structure. By using the time domain nature of the code, it was possible to temporarily isolate the different features that caused the various reflection points. 


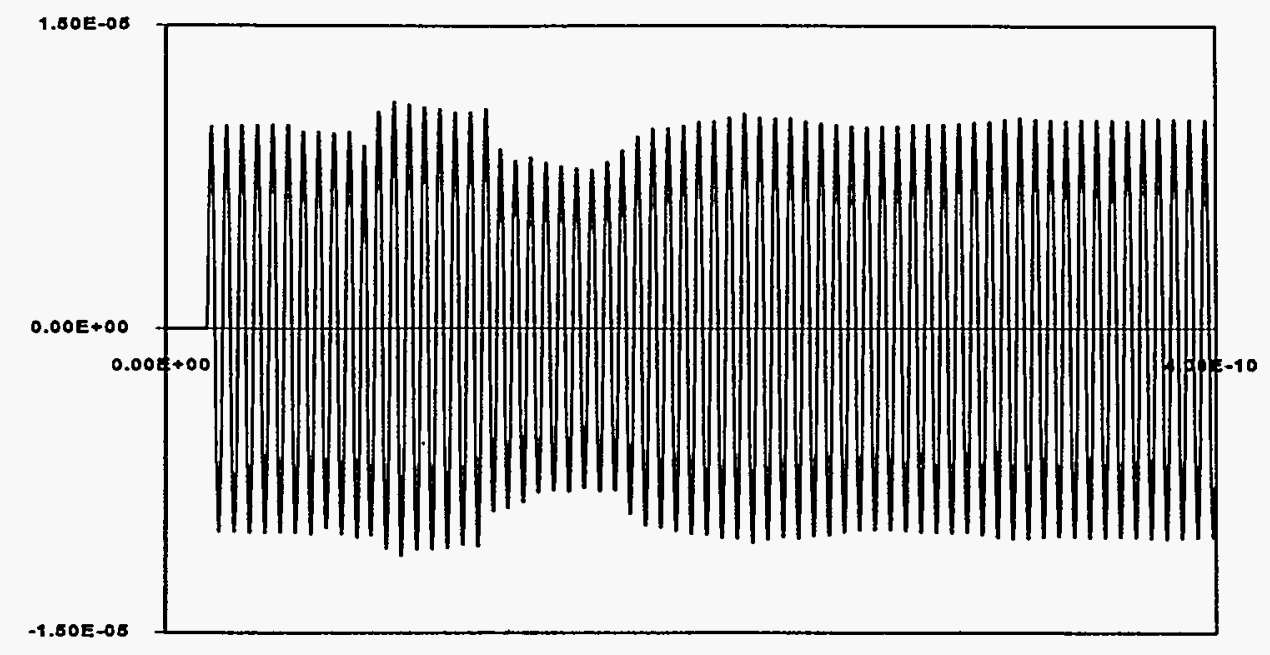

FIGURE 6. Temporal field values at a peak spatio-temporal measurement point in a mismatched model show the earily time $\mathrm{CW}$ wave passing the measurement point, the resulting reflections off of the leading portion of the window, later reflections from features further downrange, and the resulting stabilization result.

It is seen that in the earily time portion of the returned signal, the scattering off of the metal leading edge surfaces of the cooling fins is quite dramatic. It is both beneficial (for late time reductions in the reflected field) and detrimental (for the early time field concentrations) that the $\mathrm{CW}$ constructive and destructive interference comes about due to the addition of the dielectric portion of the window (i.e. the real purpose of the window). This tends to reduce these later time and quiescent values. It is this stabilization period which will require further work during the linking of the thermal to the electromagnetic codes to determine if the over-stress points provide serious short term heating effects. The thermal propagation time from the tips to the cooling channels will also have to be examined as part of this analysis.

$x_{i \infty} \cdots \cdot$

\section{FDTD modeling of the window}

One advantage of using time domain modeling for a $\mathrm{CW}$ problem is that the field values may be monitored during the evolution of the stabilization process. As part of previous efforts, numerous different geometries were considered for the configuration of the dielectric in the window. As was shown by the thermal modeling efforts, the cooling fin tip regions have more severe heating problems than do those of the dielectric. The previous EM models concentrated on field propagation through the window in order to evaluate different possible configurations. These configurations included numerous geometries including: 
double disk; bar-grid; thin bar-grid; triangular bar-grid; long triangular bar-grid; symmetric bar-grid; and corrugated structures. The crucial design parameters in both these and the distributed cooled window designs are the issues of manufacturability and structural integrity while operating under CW RF loads.

\section{EM modeling of the window}

For the electromagnetic modeling of the distributed cooled window, it was necessary to construct a variety of simulations so that the various parameters involved in the design could be adjusted. The initial case involved the modeling of the window to compare against the analytic solution for a simple single disk window (Figure 7).

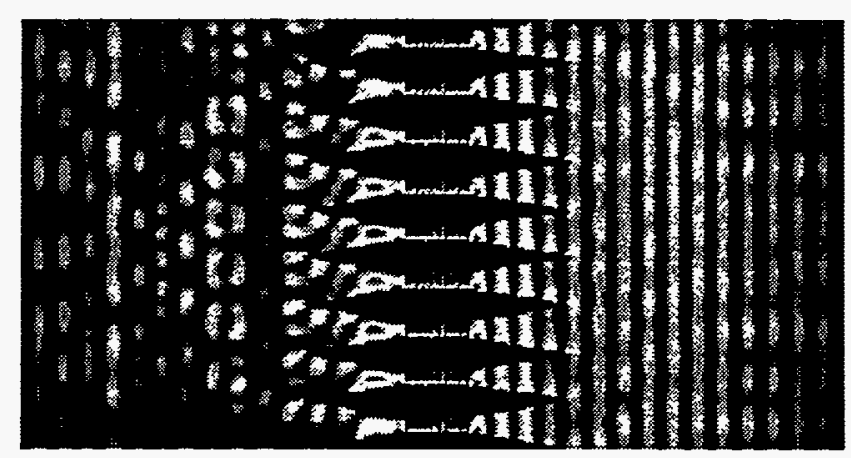

FIGURE 7. Electromagnetic field plot showing the field status at a snapshot in time. This is the $170 \mathrm{GHz}$ design with the original fin spacing.

The tip scattering effects, the continuous reflection from the taper, the large front surface dielectric reflection, and the multiple internal dielectric reflections contribute to the window's performance. These multiple effects manifest themselves in near field "mode patterns" in a region within many wavelengths from the window.

Although the reflectivity and spacial energy concentrations can combine to be quite large in places, several simulations did not find them to be larger than twice the incident field values. These effects dissipate at larger distances from the window outside of the near field and are caused by the taper pitch angle. 


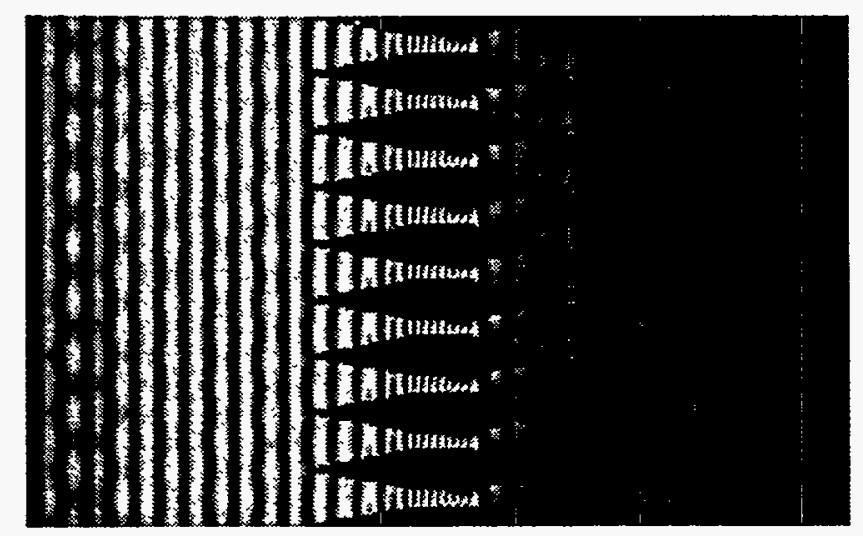

FIGURE 8. Electromagnetic field plot showing the field status at a snapshot in time with the fin spacing increased by $20 \%$ which induces off axis diffraction effects.

\section{EM calculation of power reflectivity}

By examining the analytic solution (Eqn 2) for the simple single disk window, it was noticed that there are numerous operating regions across the band (Figure 9) where such a window could potentially be used. A series of time domain $\mathrm{CW}$ models was generated to compare the operation of the distributed cooled window to that of the simple single disk window.

$$
\frac{\sin ^{2}\left(k_{z} l\right)}{\frac{4 \epsilon_{r}}{\left(\epsilon_{r}-1\right)^{2}} \sin ^{2}\left(k_{z} l\right)}
$$

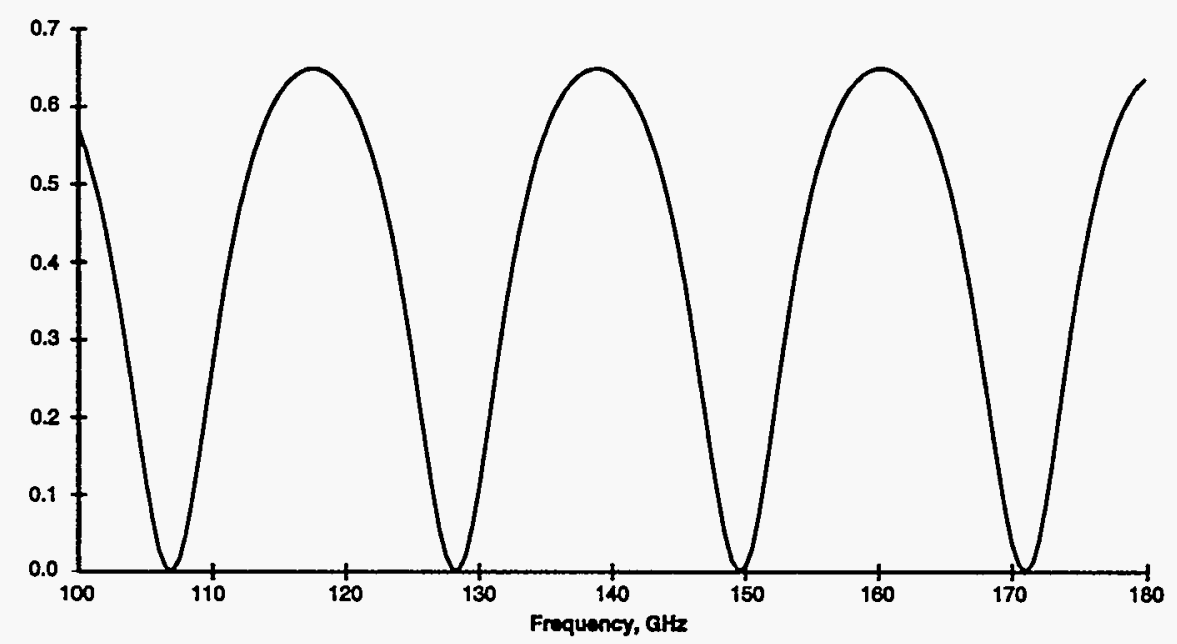

FIGURE 9. Power reflectivity curve for the simple single disk window and the modeled data points for the distributed cooled window. 


\section{CONCLUSIONS}

The distributed cooled window is designed to pass RF energy while maintaining vacuum integrity. There is some loss in the window due to ohmic heating of the niobium and absorption by the sapphire dielectric material. Heat is removed almost solely by the water coolant flowing the cooling channels. The peak temperature in the tip goes as $\tan \theta$, where $\theta$ is the angle at the base of the tip. Keeping a short distance between the tip and the cooling channel lowers the maximum tip temperature, but may cause difficulty with machinability and coolant flow.

The window's RF performance over a broad frequency band is very similar to that of the simple single disk window. At frequencies above the diffraction limit, off axis propagation tends to dominate, while at lower frequencies, tip scattering and dielectric gap phase center "mode patterns" tend to dominate the effects.

Some of the principal benefits of the distributed cooled window are it's scalability to high powers, it's structural strength, and it's low reflectivity at several frequencies of interest.

\section{FUTURE WORK}

Work on these and other window concepts is continuing. Specifically, 3D thermal analysis involving heating (including water coolant heating) and non-planar mechanical effects will be examined. The thermal propagation time from the tips to the cooling channels will also have to be examined as part of this analysis and when the EM modeling results are coupled into the thermal analysis. Additional work involving a parameter study of the fin geometry treatment and it's effects on the thermal distribution in relation to the RF reflectivity will also be performed.

\section{ACKNOWLEDGEMENTS}

The authors would like to thank Cliff Shang, of LLNL, and Dick Freeman and Dave Phelps, of General Atomics, for their past contributions, suggestions, and interest during the course of this project.

*Portions of this work were performed under the auspices of the US Department of Energy by the Lawrence Livermore National Laboratory under contract No. W-7405ENG-48. 


\section{REFERENCES}

1. Charles Moeller, General Atomics.

2. Malcolm Caplan, LLNL, private communication.

3. J. DeFord, et. al., "Development and Applications of Dispersive Soft Ferrite Models for TimeDomain Simulation," LLNL (UCRL-JC-109495), 1992.

4. S. D. Nelson, "EM modeling for GPIR using 3D FDTD modeling codes," LLNL (UCRL-ID119087), http://www-dsed.llnl.gov/documents/em/gpirmodeling.html, 1994.

5. Cliff Shang, Coorperative Research Review, LLNL, April 1995. 